\title{
Consistency Characteristics of Dispersive Clays
}

\author{
Roaa H. Ismael , Mohammed Y. Fattah ${ }^{\mathbb{D}}$, Mohammad F. Aswad \\ Materials Engineering Dept., University of Technology-Iraq, Alsina'a street, P.O Box 10066 Baghdad, Iraq. \\ *Corresponding author Email: roaa.miko@gmail.com
}

\section{H I G H L I G H T S}

- A dispersed soil has been artificially prepared by adding $\mathrm{Na} 2 \mathrm{CO} 3$ to natural clay in different proportions.

- The proportions are as follows $5 \%, 15 \%$, $25 \%, 30 \%, 35 \%$, and $40 \%$ by weight.

- The target of this investigation is to investigate the effect of degree of dispersion of the soil on Atterberg limits.

- The study showed that the percentage of dispersion increases with Atterberg's limits.

\section{A R T I C L E I N F O}

\begin{tabular}{l} 
Handling editor: Wasan I. Khalil \\
\hline Keywords: \\
Dispersion \\
$\mathrm{Na}_{2} \mathrm{CO}_{3}$ \\
Atterberg limits \\
Clay \\
Double hydrometer test
\end{tabular}

\section{Introduction}

Dispersed soil is a main participate worker involved in the failure of pipes in dikes, especially small dikes that are without filtering, with bad build overseer ion [1]. The bring about statistical study on 11192 hydraulic structures in the ground showed that (136) structures were subjected to deformation with (48\%) by surplus, $(46 \%)$ by inner corrosion and (6\%) by ground bearing failure [2]. The corrosion takes place while (shearing stress) prompted by liquid influx on the roof is big sufficient to suitable for removing grains from the flat. Opposition to corrosion is presented by precipice immersed weight i.e. (gravity forces) for (non-cohesive soils). But in (cohesive soil), the soil composition and the reaction between pore and corroding liquid at the roof is the property implicated in clay corrosion. Affecting elements on (shear stress) required for corrosion are the amount and type of clay (water content), (temperature), (organic matter), ( $\mathrm{pH})$, (thixotropy) and (type concentration of ions in the pore and eroding fluids) [3].

A specific type of soil is dispersed clay where part of the clay is corroding when water is present through the operation of breaking up pimplesinto fine grains, resulting adispersion[4]. This soil erodes quickly and unexpectedly when there is water, even if the water flow is slow. It causes instability in the excavation work. Corrosion leads to clay dispersion that relies on the metallurgy and chemical installation of clay as well as dissolved salts in pore water. The dispersed clay is known to be very corrosive because it contains a higher percentage of dissolved (sodium cations) in the pore water than in normal clay. Hence, the sodium ion creates a double layer of water that in turn surrounds the individual clay molecules. Causing increases (the repulsion forces) on (the attractive forces) so that particles easily enter the commentary when there is water [5].

Sodium is absorbed on the clay surface in a sodic soil. It is (positive and big) ion with a small charge. Positive charge ions connect the negatively charged clay grains together. Whereas, in (normal clay) soils, it is characterized by the presence of calcium ion, which is characterized by its small size and its strong charge. This ion is absorbed on the roof of clay. Water is 
added to a soda soil and attracted to sodium. The ions are moistened, which separates the plates. The role of ions linked the clay plates are skipped, the clay expansive and then spreads with water. Water between the platelets can enter the abnormal soil, leading to soil swelling $[6,7]$.

Erodibility testing for soil on earth dam should become a routine part of the subsurface exploration and testing program to identify the soil weather dispersive or non-dispersive. Samples obtained from Al-Adhaim dam- Iraq, were located in the medium plasticity range in the Unified Soil Classification, the pinhole result showed that the soil is dispersive [8].

Dispersive tests were carried out by Djokovic [9] on samples of fine-grained soils of different origins, which were used for the purpose of filling various objects: silty clay core earth fill dams "Rovni", loess from different locations and kaolinite sandy clay deposits. The dispersion tests that were carried out were crumb test, double hydrometer test pinhole test and dissolved salt content. Common identification - classification testing was done previously: determination of moisture content, particle size distribution (sieving and hydrometer method), plasticity and standard Proctor's compaction test. Soil classification was made according to Unified Soil Classification System (USCS). The identification and classification of fine-grained soil samples in terms dispersion was done. In order to establish dependencies between dispersion and the degree of compaction, the pinhole tests were performed on samples with different degrees of compaction Rc: 90, 92, 95, 98, 100 and 102\% compared to the compaction of the resulting standard Proctor compaction energy.Chemical test was performed in addition to the dispersion tests. In this test, a sample of pore water is extracted from a saturated slurry of a soil sample and analyzed for cations. At normal salt concentrations, soils with more than 60 percent of their total salts being sodium are dispersive. Soils with less than 40 percent of their total salts being sodium are usually not dispersive.

Fattah et al. [10] made amodification on the pinhole apparatus as required by specification of the American Society for Testing and Materials (ASTM D4647 - 93), which works on the basis that distilled water is passed horizontally under the influence of flow of hydraulic amount $(50 \mathrm{~mm})$ through a small hole diameter $(1 \mathrm{~mm})$ in the soil sample. The nature of the solution, which passes through the sample under the primary head $(50 \mathrm{~mm})$ gives index through which a principle to distinguish between dispersive and non-dispersive clays, where the flow of clay diffuses dark and increasingly hole diameter that operate in the sample quickly resulting in an increase in the flow rate. The apparatus has been modified to take into consideration any angle with the horizon (from zero up to $90^{\circ}$ ) and thus can represent cases of flow closer to reality, as the standard apparatus is applicable to prove horizontally, i.e., it is assumed inevitably flow horizontal (horizontal flow) and direction perpendicular to the layers of the soil. Since the primary application to pinhole is in the earth dams, the flow of water through the earth dam rarely is horizontal. So the current development represents more accurately practice. In addition, the modification included a method to prepare the sample in the compaction model in a manner similar to standard compaction test when the moisture content and dry density are required. A water tank has been developed through mobile sitting on a metal platform to achieve different mobile hydraulic heads provided by the test specification.

The response of using Aluminum sulphate, lime, cement, asphalt, liquid chemicals and sodium hydroxide, sodium silicate among others as chemical additives or stabilizers in stabilization clay sand combination of two or more of these additives or stabilizers, encouraging results were reported from these studies. These stabilizers or additives are not readily available locally; those readily available are costly which make their usage expensive. There is therefore the need for replacement of these stabilizers or additives with local substitutes which can lead to the development of a durable and cheap building material for many poor communities.

There are a number of laboratory tests for identification of dispersive clays. Numerous inquiries have been undertaken to improve recognition methods to (dispersed clay), as it cannot be determined through traditional (laboratory index tests) such as (Atterberg limits), (visible classification), (specific gravity), or (gradient). Literature notes showed that there are major differences in the erosion of the soil, which is possess the same (index properties) and (appearance), when these specimens were brought from one location, with few differences in distances between them [11].

The most generally performed laboratory to recognize (dispersive clays) are (the double hydrometer test), (the pinhole test), (the test of dissolved salts in the pore water), and (the crumb test).

\section{Double hydrometer test}

The grain size distributionis determined firstusing (standard hydrometer test) in which the sample of soil is disband in (distilled water) with dispersion factor and powerful mechanical instigation. An analogous fluid scale test is then performed on another sample of the same soil, but without dispersion factor and powerful mechanical instigation. The percent dispersion" is calculated by dividing (\% passing $5 \mu \mathrm{m}$ using test without dispersion factor and powerful mechanical instigation), by (\% passing $5 \mu \mathrm{m}$ size with dispersion factor and powerful mechanical instigation), and (multiplying the result by [12].

The (degree of dispersion) is calculated from the results of an examination (double hydrometer test) according to the following:

$$
\mathrm{D}=\frac{\% \text { passing } 5 \boldsymbol{\mu m} \text { (without disper santagent) }}{\% \text { passing } 5 \mu \mathrm{m} \text { (standard) }} * 100
$$

The objective of the present study is to investigate the effect of dispersive ions on the consistency characteristics (Atterberg limits) of clays. The dispersive clays are artificially prepared by adding different percentages ofsodumecarbonat $\mathrm{Na}_{2} \mathrm{CO}_{3}$ to the natural clay. 


\section{Experimental Study}

\subsection{Materials used}

\subsubsection{The natural soil}

The soil sample was taken from a site to the east of Baghdad city, Standard tests were conducted to determine the (physical and chemical) properties of the soil as shown in Table 1.

\subsection{Sodium carbonate $\left(\mathrm{Na}_{2} \mathrm{CO}_{3}\right)$}

Sodium carbonate is a chemical compound whose molecular formula is $\mathrm{Na}_{2} \mathrm{CO}_{3}$, also known as washing carbonate. It takes the form of a white powder, and is found in nature as a mineral, and sodium carbonate solutions are alkaline solutions, used as a dispersion of soil.

\subsection{Preparation of artificial dispersive clay}

The natural clay soil was mixed with different percentages by weight of $\mathrm{Na}_{2} \mathrm{CO}_{3} ; 5 \%, 15 \%, 25 \%, 30 \%, 35 \%$ and $40 \%$ to prepare artificial dispersive soils.It was found by trials and depending on the literature that $\mathrm{Na}_{2} \mathrm{CO}_{3}$ increases the clay dispersion. Fattah et al. [19] found that after 24 hours of soaking the soil in distilled water, the totaldissolved salts will reach about $95 \%$ of the actual amount (after 3 days).

These soil samples were examined by using double hydrometer test to identify their dispersion characteristics. Table 2 presents the results of dispersion test. Figurers 1 to 7 show the grain size distribution for the clay with different $\mathrm{Na}_{2} \mathrm{CO}_{3}$ percentages.

Table 1: Chemical and physical properties of the natural soil used.

\begin{tabular}{lcll}
\hline & Index Property & Value & Specification \\
\hline Specific gravity & $(\mathrm{Gs})$ & 2.7 & ASTM D 854[13] \\
Liquid Limit & $(\mathrm{L} . \mathrm{L}) \%$ & 44 & ASTM D 4318[14] \\
Plastic Limit & $(\mathrm{P} . \mathrm{L}) \%$ & 22 & ASTM D 4318[14] \\
Gravel & $(\mathrm{G}) \%$ & 0 & ASTM D 422[15] \\
Sand & $(\mathrm{S}) \%$ & 3 & ASTM D 422[15] \\
Silt & $(\mathrm{M}) \%$ & 22 & ASTM D 422[15] \\
Clay & $(\mathrm{C}) \%$ & 75 & ASTM D 422[15] \\
Soil classification USCS & & $\mathrm{CL}$ & ASTM D 2487[16] \\
Maximum dry unit weight & $\mathrm{kN} / \mathrm{m}^{3}$ & 17.3 & ASTM D698 [17] \\
Optimum water content & $\%$ & 17 & ASTM D698 [17] \\
Gypsum content & $\%$ & 1.24 & B.S. 8004 - 1990 [18] \\
SO ${ }_{3}$ content & $\%$ & 0.580 & B.S. 8004 - 1990 [18] \\
Organic matter & $(\mathrm{O} \% \mathrm{M}) \%$ & 1.69 & B.S. 8004 - 1990 [18] \\
(pH) value & & 9.02 & B.S. 8004 - 1990 [17] \\
\hline
\end{tabular}

USCS: Unified Soil Classification System

Table 2: $\quad$ Dispersion characterization of samples from double hydrometer test.

\begin{tabular}{lccc}
\hline Soil & $\begin{array}{c}<\mathbf{5 \mu m} \text { (without } \\
\text { dispensing) } \%\end{array}$ & $\begin{array}{c}<\mathbf{5} \boldsymbol{\mu m} \text { (with } \\
\text { dispersing) } \%\end{array}$ & $\begin{array}{c}\text { Percent } \\
\text { dispersion }\end{array}$ \\
\hline Normal Clay & 0.062 & 0.665 & 9.4 \\
Normal Clay with $5 \% \mathrm{Na}_{2} \mathrm{CO}_{3}$ & 0.126 & 0.76 & 16.6 \\
Normal Clay with $15 \% \mathrm{Na}_{2} \mathrm{CO}_{3}$ & 0.2522 & 0.819 & 31 \\
Normal Clay with $25 \% \mathrm{Na}_{2} \mathrm{CO}_{3}$ & 0.35 & 0.868 & 40 \\
Normal Clay with $30 \% \mathrm{Na}_{2} \mathrm{CO}_{3}$ & 0.353 & 0.79 & 45 \\
Normal Clay with $35 \% \mathrm{Na}_{2} \mathrm{CO}_{3}$ & 0.43 & 0.68 & 63 \\
Normal Clay with $40 \% \mathrm{Na}_{2} \mathrm{CO}_{3}$ & 0.469 & 0.7 & 67 \\
\hline
\end{tabular}

*with:with mechanical agitation, and with a chemical dispersant.

*without:without mechanical agitation, and without a chemical dispersant. 


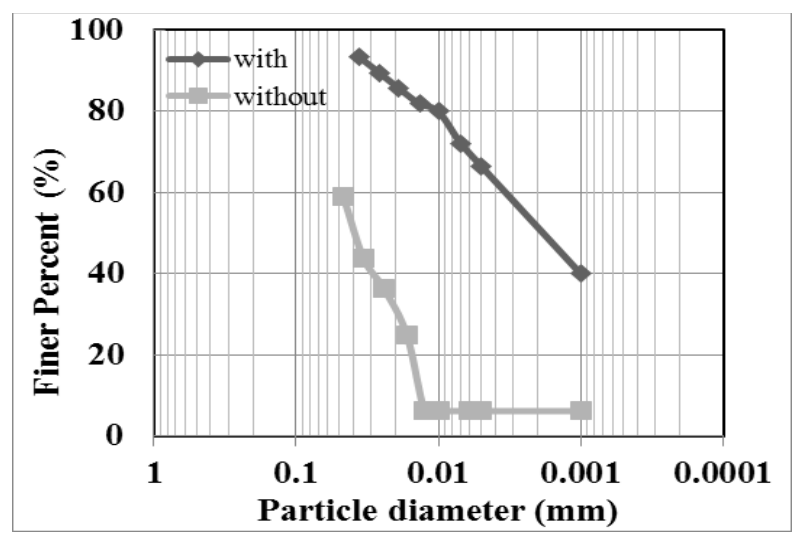

Figure 1: The hydrometer test results for the natural clay

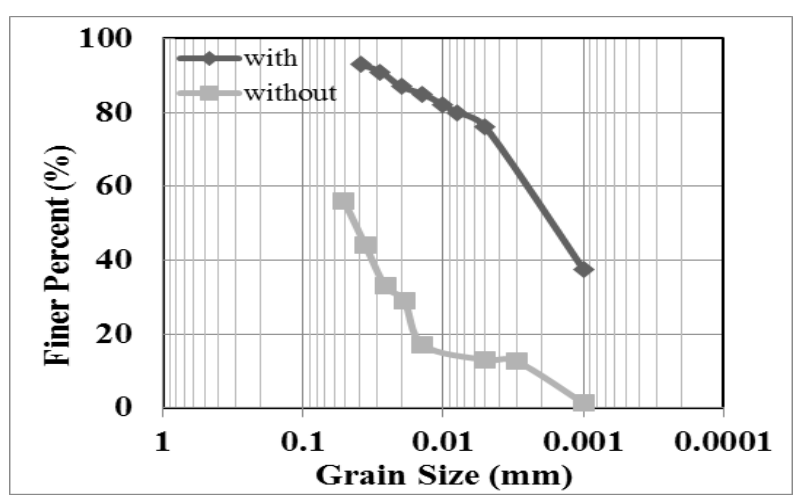

Figure 2: Grain size distribution for dispersive clay with $5 \% \mathrm{Na}_{2} \mathrm{CO}_{3}$

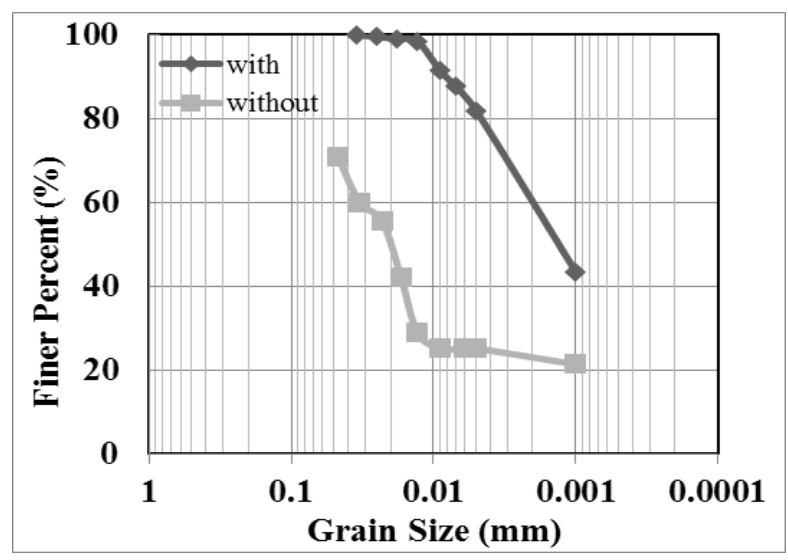

Figure 3: Grain size distribution for dispersive clay with $15 \% \mathrm{Na}_{2} \mathrm{CO}_{3}$

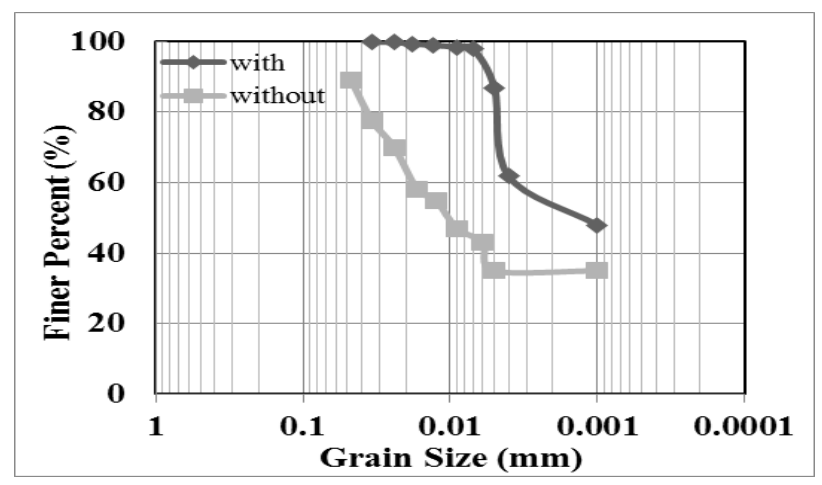

Figure 4: Grain size distribution for dispesive clay With $25 \% \mathrm{Na}_{2} \mathrm{CO}_{3}$ 


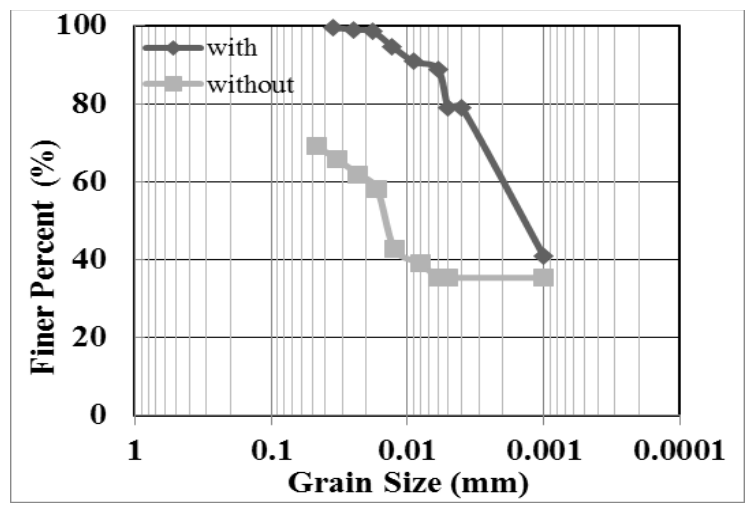

Figure 5: Grain size distribution for dispersive clay with $30 \% \mathrm{Na}_{2} \mathrm{CO}_{3}$

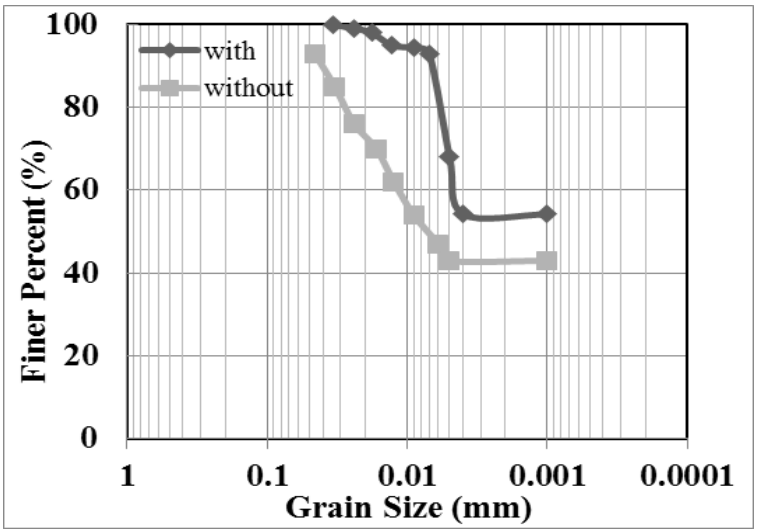

Figure 6: Grain size distribution for dispersive clay with $35 \% \mathrm{Na}_{2} \mathrm{CO}_{3}$

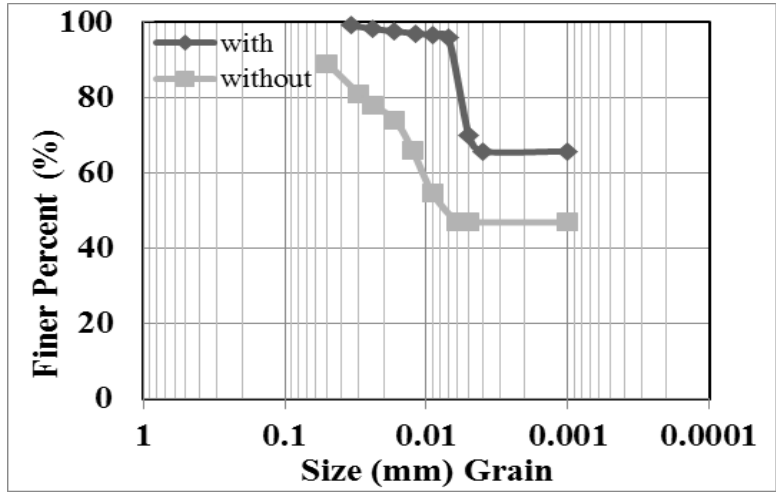

Figure 7: Grain size distribution for dispersive clay with $40 \% \mathrm{Na}_{2} \mathrm{CO}_{3}$

Figure 8 presents the differencing of Atterberg limits:plasticity index, plastic limit, and liquid limit with the percentage of $\mathrm{Na}_{2} \mathrm{CO}_{3}$. It is evident that there is a decrease in liquid limit below $(15 \%)$ of $\mathrm{Na}_{2} \mathrm{CO}_{3}$. This may be due to the ability of $\mathrm{Na}_{2} \mathrm{CO}_{3}$ to absorb some of the water included in the soil pores. After this percent, there is few increase in (liquid limit) but when $\mathrm{Na}_{2} \mathrm{CO}_{3}$ exceeds $(30 \%)$, a rapid increase in (liquid limit) was observeddue to dispersive ability of soil caused by $\mathrm{Na}$ ions which also leads to increase soil particles absorption to water.

Figure 9 presents a relation between Atterberg limits and percent of dispersion of the clay. The same trend in the previous figure is obtained. The plastic limit is not affected noticeably by the clay dispersion. Bakir et al. [20] concluded that the maximum head caused by the flow of the acid through the soil decreases with the increase of the coefficient of permeability and the plasticity index of the polluted soil. 


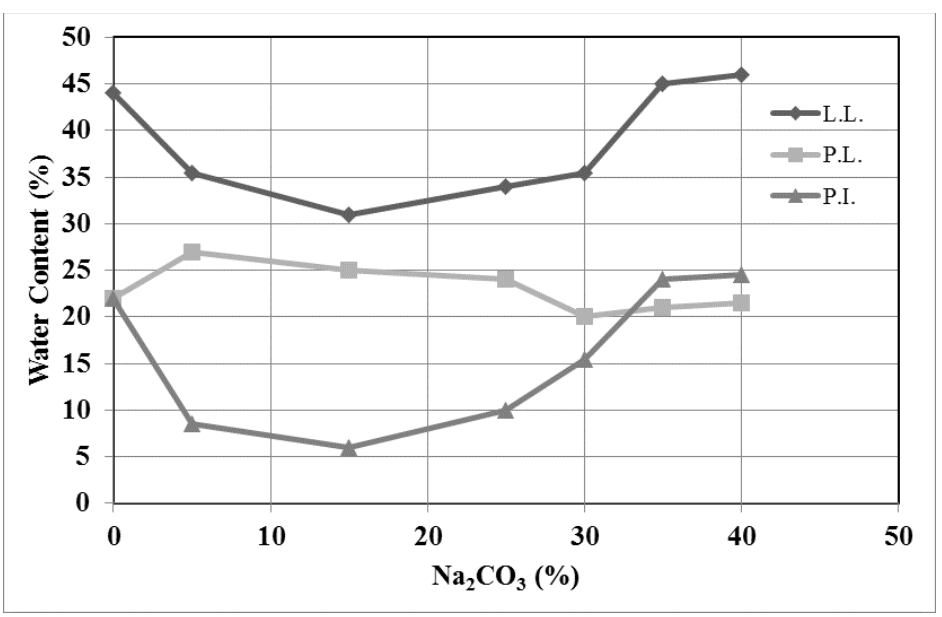

Figure 8: Relationship between $\mathrm{Na}_{2} \mathrm{CO}_{3}$ and Atterberg limits

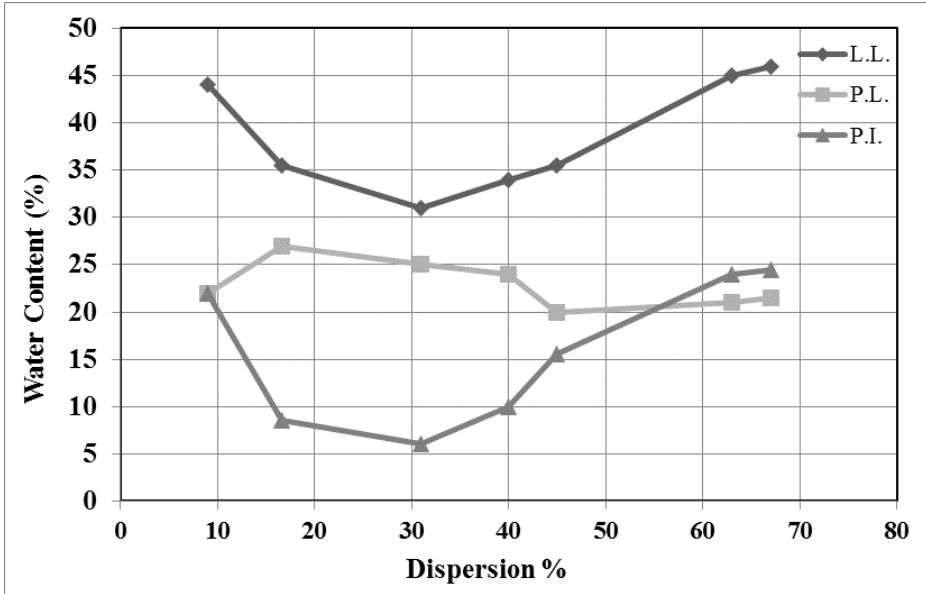

Figure 9: Relationship between dispersion and Atterberg limits

\section{Conclusions}

1) When adding $\mathrm{Na}_{2} \mathrm{CO}_{3}$ in different concentrations to the soil, the dispersion percent will increase significantly, and its effective ratio will be in concentration of $35 \%$, where dispersion may increase $600 \%$ as present in Table 2 .

2) There is a relationship with dispersion factor and plasticity index.Also, many soils have the same properties; plasticity index,but differ in (degree of dispersion).

3) The dispersion of clay has effect on the plastic limit less than that on the liquid limit,this indicates that the $\mathrm{Na}_{2} \mathrm{CO}_{3}$ is affected when there is water.

\section{Author contribution}

All authors contributed equally to this work.

\section{Funding}

This research received no specific grant from any funding agency in the public, commercial, or not-for-profit sectors.

Data availability statement

The data that support the findings of this study are available on request from the corresponding author.

\section{Conflicts of interes}

The authors declare that there is no conflict of interest.

\section{References}

[1] Fell, R., MacGregor, Stapledon, D. ,Foster, M. , Geotechnical engineering of embankment dams, second edition, Taylor Francis Group,London,UK., (2015)

[2] Rosquoët,F., Bendahmane, F., Marot, D., and Alexis, A., Experimental Characterization of internal erosion on sandy clay samples $23^{\text {rd }}$ Academic Symposium of Civil Eng., (2005).

[3] T. S.Umesha, S. V. Dinesh, and P. V. Sivapullaiah, Characterization of dispersive soils, Mater. sci. appl., 2 (2011) 629-633. https://doi.org/10.4236/msa.2011.26085 
[4] Forrest, T. G. , Engineering and design - Laboratory soils testing, Appendix XIII: Pinhole erosion test for identification of dispersive clays Dep. of Tee army, Washington, U.S.A.,(1980).

[5] C. H. McElroy, Using hydrated lime to control erosion of dispersive clays, Lime for Environmental Uses. Gutschich K G. ASTM. STP., 931(1987) 100-114. https://doi.org/10.1520/STP23155S

[6] Anon, R., Effects of sodicity and salinity on soil structure, SOILpak for dryland farmers on the red soil of Central Western NSW, NSW Dept., Primary Industry,(1999).

[7] M. Y.Fattah, N. M. Salim, E. J.Irshayyid, Experimental Study on Compressibility, Volume Changes, Strength and Permeability Characteristics of Unsaturated Bentonite-Sand Mixtures, Eng. Technol. J., 34 (2016) 1308-1323.

[8] Hamoodi, M., Filter Requirements for cohesive soil used in earth dams,(1996).

[9] Habibnia, A., Rahimipour, G., \& Ranjbar, H.,Equivalence assessment and leveling of geochemical datasets to generate integrated geochemical maps: Application to mineral exploration, J. Geochem. Explor., 212 (2020)106507. https://doi.org/10.1016/j.gexplo.2020.106507

[10] M. Y. Fattah,H. A. Omran,T. M.Abdulatif, Modification of Pinhole Apparatus for Identification and Classification of Dispersive Clay Soils, Journal of Eng. and Dev., 18 (2014) 181-201.

[11] Vyas, S. , N.Phougat,P. Sharma, and M. Ratnam, Stabilization of dispersive soil by blending polymers, Int. J. Earth Sci. Eng., 04 SPL( 2011) 52-54.

[12] ASTM D4221 - 18 Standard Test Method for Dispersive Characteristics of Clay Soil by Double Hydrometer, ASTM International., (ASTM).

[13] ASTM D 854, Standard Test Method for Specific Gravity, ASTM International., (ASTM).

[14] ASTM D 4318, Standard Test Method for Liquid Limit, Plastic Limit, and Plasticity Index of Soil, ASTM International., (ASTM).

[15] ASTM D 422, Standard Test Method for Particle Size Analysis of Soils, ASTM International., (ASTM).

[16] ASTM D2487, Standard Test Method for Classification of Soils for Engineering Purposes (Unified Soil Classification System), ASTM International., (ASTM).

[17] ASTM D698, Standard Test Methods for Laboratory Compaction Characteristics of Soil Using Standard Effort. ASTM International., West Conshohocken, PA.

[18] British Standards, BS: 8004, Code of Practice for Foundation, Standards Institution, London, (2004).

[19] M. Y.Fattah, M. Th. Al-Hadidi,B. A Ali, Optimization of the Time Required for Determination of the Total Dissolved Salts in Soil, Eng. Technol. J.,32 (2014) 03272-3283. Special issue on the 1st International Scientific Conference on Environment and Sustainble Development (ISCESD 2013), 29-30 Dec, 2013.

[20] H. H Bakir, F. H. Rahil, M. Y.Fattah, M. A. Al-Neami, Effect of Soil Consistency of Cohesive Soils on Flow Characteristics of Acids, Eng. Technol. J., 26 (2008)1185-1200. 